\title{
Prevalence of ventilator-associated pneumonia through analysis of tracheobronchial secretions
}

\author{
Prevalência de pneumonia associada à ventilação mecânica por meio de análise das \\ secreções traqueobrônquicas
}

Elenice Gomes Ferreira ${ }^{1}$, André Kimura ${ }^{1}$, Danielly Fernandes de Ramos ${ }^{1}$, Pascoal Leite de Albuquerque ${ }^{1}$, Mateus Dias Antunes ${ }^{1}$, Daniel Vicentini de Oliveira ${ }^{2}$

Objective: to verify the prevalence of pneumonia associated with mechanical ventilation through the collection and analysis of tracheobronchial secretions. Methods: an observational study with 13 male patients. The scale of Acute Physiology and Chronic Health Evaluation and the Clinical Pulmonary Infection Score were applied after 72 hours of orotracheal hospitalization. Results: an average score of 33 points was observed, that is, these patients presented on average a $75 \%$ chance of death. Staphylococcus aureus $(23.07 \%)$ and Klebsiella pneumoniae $(15.38 \%)$ were found as the most prevalent microorganisms. Conclusion: the prevalence of ventilator-associated pneumonia was $25 \%$ of the cases and the most prevalent microorganisms were Klebsiella pneumoniae and Staphylococcus aureus.

Descriptors: Physical Therapy Department, Hospital; Intensive Care Units; Nursing.

Objetivo: verificar a prevalência da pneumonia associada à ventilação mecânica por meio da coleta e análise das secreções traqueobrônquicas. Métodos: estudo observacional com 13 pacientes do sexo masculino. Foi aplicada a escala de Acute Physiology and Chronic Health Evalution e o Clinical Pulmonary Infection Score após 72 horas de internação orotraqueal. Resultados: observou-se uma pontuação média de 33 pontos, ou seja, estes pacientes apresentaram em média $75 \%$ de chance de óbito. Foram encontradas como microorganismos de maior prevalência o Staphylococcus aureus (23,07\%) e Klebsiella pneumoniae (15,38\%). Conclusão: a prevalência de pneumonia associada à ventilação mecânica foi de $25 \%$ dos casos e que o microorganismo de maior prevalência foi Klebsiella pneumoniae e Staphylococcus aureus.

Descritores: Serviço Hospitalar de Fisioterapia; Unidades de Terapia Intensiva; Enfermagem.

\footnotetext{
${ }^{1}$ Centro Universitário de Maringá. Maringá, PR, Brazil.

${ }^{2}$ Universidade Estadual de Campinas. Campinas, SP, Brazil. 


\section{Introduction}

Ventilator-associated pneumonia in Brazil is the most frequent cause of infections, representing $60.0 \%$ of the main factors to acquire such complication. It occurs frequently in hospitalized patients admitted to intensive care units and submitted to mechanical ventilation. It can be classified as early when occurring up to the fourth day of intubation and as late when occurring after the fifth day ${ }^{(1)}$.

Ventilator-associated pneumonia is classified as early ( $\leq 4$ days of hospitalization) and late (mechanical ventilation $\geq 48$ hours and hospitalization $\geq 5$ days). Thus, the etiology of each patient depends on a series of factors related to local epidemiology, length of stay, use of antimicrobials and the severity of the infection $^{(2)}$.

The presence of the endotracheal tube can cause a series of complications due to the breakdown of the natural protective barrier, affecting the cough reflex, the reduction of the ciliary cleaning, and it can be a means of access of microorganism to the lower respiratory tract ${ }^{(3)}$.

Among the risk factors, it is highlighted the abusive use of antimicrobials and anti-inflammatory drugs due to the symptomatology presented after the installation of ventilator-associated pneumonia, fever, leukocytosis and purulent tracheobronchial secretion. Drugs such as aminoglycosides (amikacin), $3^{\text {rd }}$-generation cephalosporin (cefetriaxone), $4^{\text {th }}$ generation cephalosporin (cefepime), penicillins with B-lactamase inhibitors, quinolones and carbapenem exert selective pressure on certain classes of microorganisms ${ }^{(4-5)}$. It has been reported the appearance of drug-resistant bacteria resistant, which requires more intensive care for each case's severity ${ }^{(6)}$.

The colonization of microorganisms is not restricted to the upper and lower airways, but also in the oral cavity due to lack of hygiene, mainly of patients with reduced level of consciousness ${ }^{(7)}$. The microorganisms frequently found in patients under mechanical ventilation are: Klebsiella spp; non-fermenting Gram-
-Negative Bacillus; Staphylococcus aureus and Pseudomonas aeruginosa ${ }^{(8)}$.

The components of the ventilator circuit are often contaminated through handling or time of use, related to external factors such as care of heat and humidity filters, having as main function the maintenance of the normal physiological conditions of the lower airways $^{(9)}$.

Prevention methods of risk factors for pneumonia associated with mechanical ventilation have been advocated, such as: preference for orotracheal intubation, adequate maintenance of the cuff pressure, position of the tube, replacement of the heat and humidity exchangers, sterile conditions for bronchial aspiration and performing it only when necessary, avoiding instilling saline solution prior to aspiration, head elevation from $30^{\circ}$ to $45^{\circ}$ degrees, use of enteral nutrition, oral hygiene, glycemic control ${ }^{(10)}$.

To evaluate the severity of the disease quantified by the degree of physiological abnormalities of the patients in the intensive care unit, the Acute Physiology and Chronic Health Evaluation scale is used, which determines the individual's risk of mortality ${ }^{(11)}$.

The Municipal Hospital of Maringá is a public service that does not have an intensive care unit yet. For this reason, it supports emergency situations in a six-bed emergency room, and in many cases patients end up requiring the use of invasive mechanical ventilation. Due to the lack of beds in other reference hospitals to refer to intensive care, patients end up receiving this care by the multidisciplinary staff of the hospital itself (physician, nurse, nursing technicians, nutritionist, psychologist and physiotherapist) in order to allow weaning of invasive mechanical ventilation, reduce the risk of nosocomial infection and ventilator-associated pneumonia. However, as there was no survey on the rates of ventilator-associated pneumonia in this hospital, this study aims to answer the following guiding question: what is the prevalence of ventilator-associated pneumonia, after collection and analysis of bronchial secretions?

Thus, the present study aimed to verify the 
prevalence of pneumonia associated with mechanical ventilation through the collection and analysis of tracheobronchial secretions.

\section{Methods}

This is a quantitative, observational study that was conducted in the emergency room of the Municipal Hospital of Maringá, PR, Brazil, from September 2013 to August 2014.

As inclusion criteria, patients could be of both sexes and should be under mechanical ventilation. Patients who were admitted to the unit for community pneumonia were excluded. The sample was then composed of 13 patients.

Within the first 24 hours of admission of patients in the emergency room of the Municipal Hospital of Maringá, Brazil, it was surveyed in the medical records the gender, age group and clinical diagnosis of patients. It was applied the scale of Acute Physiology and Chronic Health Evaluation ${ }^{(11)}$ in which the physiological variables raised at the time of hospitalization were: temperature, blood pressure, heart rate, respiratory rate, oxygenation, blood gas, sodium, potassium, creatinine, leukocytes and hematocrit, Glasgow scale, age score and chronic disease score, which were added for determining the severity of the patient's condition, and based on the score of Acute Physiology and Chronic Health Evaluation relating the probability of death of the patient.

The Clinical Pulmonary Infection Score was applied at 72 hours of orotracheal intubation, including body temperature, leucometry, oxygenation parameters and chest X-ray, taking into account the semiquantitative culture of the tracheal secretion, which greatly increases specificity and sensitivity of the diagnosis. The maximum score of that tool is 12 , and values greater than 6 are correlated with ventilator-associated pneumonia.

The collection of the secretions for analysis was performed after 72 hours of orotracheal intubation, and those patient stayed at least six hours without receiving this procedure, which is a technique performed by the researchers using a sterile collection bottle, that is, a container with two holes: one of which is connected to the vacuum cleaner (vacuum) and the other is connected to a sterile aspiration nozzle No. 14. At the time of collection, procedure gloves were used and also, in the dominant hand, a sterile plastic glove to handle the aspiration probe. After the collection, the bottle was sealed and sent to the Teaching and Research Laboratory in Clinical Analyzes, of the State University of Maringá, for an incubation analysis. The results of the exams were sent to the hospital and thus the researchers had access for analysis.

The patients undergoing this procedure did not suffer any type of risk, since it is a sterile procedure, without contamination, and that is performed routinely inside the emergency room of this hospital by a trained team.

The data were analyzed in the software Statistical Package for the Social Sciences 22.0. Descriptive and inferential statistics were used. Frequency and percentage were used for the categorical variables. For the numerical variables, the normality of the data was initially verified through the Shapiro-Wilk test. The Pearson's Correlation Coefficient (normal data) was used to verify the correlation between the Acute Physiology and Chronic Health Evaluation score and the Clinical Pulmonary Infection Score. The significance was set at $\mathrm{p}<0.05$.

The study complied with the formal requirements contained in the national and international regulatory standards for research involving human beings.

\section{Results}

During the study period, 43 patients who needed orotracheal intubation for invasive ventilatory support were admitted to the emergency room of the Municipal Hospital of Maringá. Of these, 70.0\% (n = 30) were excluded from the study because they were admitted to the emergency room with diagnosis of 
pneumonia, or due to transfer to another reference hospital, death before collection of the biological material, or before completing the 72 hours necessary for the collection of secretion.

Thirteen patients were evaluated, with a mean age of $70.76 \pm 11.76$, and prevalence of males.

Staphylococcus aureus (23.1\%) and Klebsiella pneumoniae $(15.4 \%)$ were found to be the most prevalent microorganisms in the culture of tracheal secretions, being $7.7 \%$ isolated and a single sample and 7.7\% associated with Escherichia coli/Haemophilus influenzae; $38.9 \%$ did not present bacterial culture (Table 1).

Table 1 - Prevalence of microorganisms found in the culture of tracheal secretions

\begin{tabular}{|c|c|c|}
\hline Microorganisms & $\%$ & $95 \% \mathrm{CI}$ \\
\hline No bacterial culture & 38.9 & 21.4-71.4 \\
\hline Staphylococcus aureus & 23.1 & $0-50.0$ \\
\hline Pseudomas aeruginosa & 7.7 & $0-21.4$ \\
\hline Klebisiella pneumoniae & 7.7 & $0-35.7$ \\
\hline $\begin{array}{l}\text { Klebisiella pneumoniae/Escherichia coli/Hae- } \\
\text { mophilus influenzae }\end{array}$ & 7.7 & $0-21.4$ \\
\hline Stanotrophomonas maltophilia & 7.7 & $0-21.4$ \\
\hline Staphylococcus epidermidis & 7.7 & $0-21.4$ \\
\hline
\end{tabular}

When analyzing the Acute Physiology and Chronic Health Evalution Score of these patients in the first 24 hours of admission, it was observed a minimum score of 15 and a maximum of 42 , the average being 33 points, that is, these patients had an average of $75,0 \%$ chance of death.

When analyzing the mean of the Clinical Score of Pulmonary Infection, in 10 cases the score was less than six points, that is, there was no relation with the ventilator-associated pneumonia. However, three patients who presented a probability of $85.0 \%$ of death by the Acute Physiology and Chronic Health Evaluation had the Clinical Score of Pulmonary Infection equal to or greater than 6 points, that is, there was an association with pneumonia associated with mechanical ventilation in $23.0 \%$ of cases.

When correlating the score of Acute Physiology and Chronic Health Evaluation with the Clinical Pulmonary Infection Score, $\mathrm{r}=0.3975$ was found, presenting a mean correlation $(\mathrm{p}<0.01)$.

\section{Discussion}

At the Municipal Hospital of Maringá, patients who needed hospitalization in the emergency unit performed physiotherapy twice a day, contributing to an improvement in the patients' condition, which could justify the number of exclusions in the study due to extubation and improvement of the clinical picture.

The importance of physical therapy together with a multidisciplinary team within the Intensive Care Unit is extremely relevant to patient recovery. Among the techniques used by the physiotherapist there is mechanical ventilatory assistance, tracheal aspiration and early mobilization ${ }^{(12)}$. Such actions promote the reduction of hospitalization time and the patient's early recovery ${ }^{(13)}$.

Of the total number of patients admitted to the emergency unit of the Hospital studied, there was a predominance of males, which was also found in another study ${ }^{(14)}$. This shows the neglect of men to their own health, not seeking the health services for periodic monitoring, which would avoid more serious complications $^{(15)}$.

Among the exclusions due to death, nine had a mortality probability of $85.0 \%$ by the Acute Physiology and Chronic Health Evaluation scale and only one had a 55.0\% risk of death, corroborating with other studies $^{(16)}$ that reported that scores above $20.0 \%$ revealed a high death rate.

Ventilator-associated pneumonia is a problem commonly found worldwide, with a high mortality rate $(10.0 \%)^{(17-19)}$. About nine to $27.0 \%$ of patients under mechanical ventilation develop such a compli- 
cation $^{(20)}$, whose prevalence is consistent with the result $(25.0 \%)$ obtained in the present study. However, this can be avoided with preventive measures: hand hygiene and oral cavity hygiene; head elevation, bronchoaspiration prevention; aspiration of the secretion only when necessary and cuff pressure control ${ }^{(10)}$. At the study site, such measures are taken daily by the emergency room staff to minimize the likelihood of patient contamination.

When verifying each case of the group without bacterial culture (five patients), it was found a high mortality rate and severity of the clinical picture: three patients with $85.0 \%$, one with $55.0 \%$ and one with $40.0 \%$. These data show that the severity of the patient's clinical condition, immunological condition and pre-disposition to infection of microorganisms, demonstrating the importance of risk identification by means of a mortality predictor through the Acute Physiology and Chronic Health Evalution scale, thus indicating its main risk factors ${ }^{(11)}$.

The types of microorganisms found in the culture corroborate with a study conducted in $2013^{(8)}$ in the hospital environment, which were Klebsiella pneumoniae (40.4\%), Pseudomonas aeruginosa (17.2\%), Staphylococcus aureus(17.2\%). The drug treatment is empirical after the previous diagnosis of pneumonia, and it is still effective in the fight against pneumonia-related bacteria, eliminating the current problem of geographic microbiological multi-drug resistance ${ }^{(6,20)}$.

The level considered serious with risk of death was presented in all patients with positive bacterial culture, ranging from $25.0 \%$ to $85.0 \%$. In the current study there was no relationship between clinical diagnosis, presence of microorganisms and clinical severity according to the Acute Physiology and Chronic Health Evaluation scale, since $100.0 \%$ of the patients analyzed had an association with 3 or more clinical complications such as diabetes mellitus, stroke, cardiac decompensation, renal insufficiency, dehydration, malnutrition, cardiogenic shock, systemic arterial hypertension or seizure. The predisposition for bacterial contamination of each individual may be related to factors related to the host and medications in use ${ }^{(5)}$. Among these patients, it is not possible to know about the history of pharmacological use as well as previous hospitalizations, thus showing multidrug resistance.

The established protocols for hospital infection control are of extreme importance, such as the culture of tracheal secretion, which was not adopted in the studied environment. Microbiological monitoring is necessary because it is determinant for the control of nosocomial infections ${ }^{(7)}$. The prevalence of Staphylococcus aureus in the studied patients is consistent with several studies ${ }^{(9-10,19)}$, which associates it with a high mortality rate. This shows the relevance of intermittent monitoring for the prevention, control and combat of epidemics.

The major limitations of the present study were related to the demand for hospitalizations, since critically ill patients that required intensive care were immediately transferred to a reference hospital with an Intensive Care Unit. However, when there was hospitalization, the referred diagnosis, most of the time, was of pulmonary infection.

\section{Conclusion}

It is concluded that the prevalence of ventilator-associated pneumonia is relatively high, through analysis of tracheobronchial secretions, and that the most prevalent microorganism was Klebsiella pneumoniae and Staphylococcus aureus. There was a prevalence of ventilator-associated pneumonia in $25 \%$ of cases and a mean correlation between the severity of the disease, according to the Acute Physiology and Chronic Health Evaluation scale, and the occurrence of ventilator-associated pneumonia. These data reinforce that even when patients are being treated in an emergency room, preventive measures are extremely important in the control of infections. 


\section{Collaborations}

Kimura A and Ramos DF contributed to project design and data analysis and interpretation. Albuquerque PL and Antunes MD contributed in the writing of the article and relevant critical review of the intellectual content. Oliveira DV and Ferreira EG contributed to the final approval of the version to be published.

\section{References}

1. Abbasina M, Bahrami N, Bakhtiari S, Yazdannik A, Babaii A. The Effect of a Designed Respiratory Care Program on the Incidence of VentilatorAssociated Pneumonia: A Clinical Trial. J Caring Sciences; 2016;5(2):161-7.

2. Kadosaki LL, Souza SF, Borges JCM. Análise do uso e da resistência bacteriana aos antimicrobianos em nível hospitalar. Rev Bras Farmac. 2012; 93(2):128-35.

3. El-Hage-Sleiman AK, Hanna-Wakim R, Kanj $\mathrm{S}$, Sharara-Chami R Carneiro $\mathrm{M}$ et al. Deviceassociated infections in the pediatric intensive care unit at the American University of Beirut Medical Center. J Infect Dev Ctries. 2016; 10(6):554-62.

4. Klompas M, Berra L. Should Ventilator-Associated Events become a Quality Indicator for ICUs? Respiratory Care. 2016; 62(6):723-36.

5. Cruz FLC, Meneses MRR, Serra SC, Barbosa MCG. Pneumonia associada a ventilação mecânica: medidas preventivas. Rev Pesq Saúde. 2011; 12(1):56-9.

6. Wang J, Li DX, Yu CX, Huang S, Liang YQ. Analysis of risk factors of ventilator-associated pneumonia in an intensive care unit. Nan fang yi ke da xue xue bao - Journal of Southern Medical University, 2016; 36(5):719-23.

7. Lima MRS, Soares NS, Mascarenhas MDM, Amaral EJLS. Intervenção em surto de Klebsiella pneumoniae produtora de betalactamase de espectro expandido (ESLB) em unidade de terapia intensiva neonatal em Teresina, Piauí. Epidemiol Serv Saúde. 2014; 23(1):177-82.
8. Batista OMA, Santos MSG, Alexandria FED, Madeira MZA, Valles ARMC, Souza AFL. Sensibilidade de germes relacionados à pneumonia associada à ventilação mecânica. R Pesq: Cuid Fundam Online. 2013 [citado 2016 ago 31]; 5(6):224-33. Disponível em: http://www.seer.unirio.br/index. php/cuidadofundamental/article/view/3447

9. Steward S, Muszynski JA. Ventilator-Associated Pneumonia: Easy to Prevent or Hard to Define?. Pediatr Crit Care Med. 2016; 17(5):469-70.

10. Oliveira MLA, Veronesi CL, Goulart LS. Caracterização de recém-nascidos com hemoculturas positivas internados em unidade de terapia Intensiva neonatal. Eletr J Management Health [periódico na Internet]. 2012 [citado 2016 Jun12]; 3(2):717-29. Disponível em: http:// gestaoesaude.unb.br/index.php/gestaoesaude/ article/view/158/pdf_1

11. Naved SA, Siddiqui S, Khan HNAVED, Saad Ahmed. APACHE-II Score Correlation With Mortality And Length Of Stay In An Intensive Care Unit. J Col Physi Surg. 2011; 21(1):4-8.

12. Alves RF, Silva RP, Ernesto MV, Lima AGB, Souza FM. Gênero e saúde: o cuidar do homem em debate. Psicol: Teor Prática. 2011; 13(2):152-66.

13. Carvalho TG, Silva ALG, Santos ML, Schafer J, Cunha, LS, Santos, LJ. Relação entre saída precoce do leito na unidade de terapia intensiva e funcionalidade pós-alta: um estudo piloto. Rev Epidemiol Controle Infecç. 2013; 3(3):82- 86.

14. Favarin SS, Camponogara S. Perfil dos pacientes internados na unidade de terapia intensiva adulto de um hospital universitário. Rev Enferm UFSM. 2012; 2(2):320-9.

15. Alves AN. A importância da atuação do fisioterapeuta no ambiente hospitalar. Ens Ciênc Biol Agr Saúde. 2012; 16(6):173-84.

16. Freitas ERFS. Profile and Severity of the Patients of Intensive Care Units: Prospective Application of the APACHE II Index. Rev Latino-Am Enferm. 2010; 18(3):20-6.

17. Marini AL, Khan R, Mundekkadan S. Multifaceted bundle interventions shown effective in reducing VAP rates in our multidisciplinary ICUs. BMJ Quality Improvement Reports. 2016; 5(1):1-4. 
18. Klompas M, Branson R, Eichenwald EC, Greene LR, Howell MD, Lee G, et al. Strategies to Prevent Ventilator-Associated Pneumonia in Acute Care Hospitals: 2014 Update. Inf Contr Hosp Epidemiol. 2014; 35(8):915-36.

19. Abegg PTGM, Silva LL. Controle de infecção hospitalar em unidade de terapia intensiva: estudo retrospectivo. Semina: Ci Saúde Bio. 2011; 32(1):47-58.
20. El-Saed A, Al-Jardani A, Althagafi A, Alansari H, Alsalman J, Maskari JÁ et al. Ventilator-associated pneumonia rates in critical care units in 3 Arabian Gulf countries: A 6-year surveillance study. Am J Infect Control. 2016; 44(7):794-8. 